\title{
O RACIONALISMO CRISTÃO EM CABO-VERDE, OU OS ESPÍRITOS SEM FRONTEIRAS
}

Charlotte Plaideau ${ }^{1}$

Resumo: O racionalismo cristão é uma doutrina filosófica de caráter espiritualista, fundada em Santos (Brasil), em 1910. Hoje, porém, ela é proporcionalmente bem mais desenvolvida em Cabo Verde, assim como na diáspora cabo-verdiana, através da qual se está expandindo pelo mundo inteiro. Este artigo tenta entender, no contexto das ilhas e no funcionamento híbrido da doutrina, porque ele faz particularmente eco aos Cabo-verdianos, nativos e migrantes. Propomos a hipótese de que o sucesso da sua consolidação e transnacionalização resulta da tensão que sua prática atualiza entre uma aspiração ao racionalismo ocidental e uma ancoragem espiritualista inconfundível.

Palavras-Chave: transnacionalização, Cabo-Verde, Racionalismo Cristão.

Abstract: Christian rationalism is a philosophical and spiritualistical doctrine, founded in the city of Santos (Brazil) in 1910. Nowadays, however, it is proportionally more developed in Cape Verde than in Brazil, as well as in Cape Verdean's Diaspora, which is expanding all over the world. This article pretends to analyze, on the islands context and the hybrid functioning of doctrine, why it is particularly relevant to Cape Verdean native and immigrant people. We purpose the hypothesis that the success of consolidation and transnationalization results of the tension reaffirmed by its practice between an aspiration to Occidental rationalism and an unmistakable spiritualistical anchorage.

Keywords: transnationalization, Cape Verde, Christian Rationalism.

\footnotetext{
${ }^{1}$ Laboratoire d'anthropologie prospective - FNRS/ Université Catholique de Louvain. Esta pesquisa é financiada pelo Fundo Nacional de pesquisa científica belga (FNRS) e está ligada a um trabalho coletivo mais amplo sobre a religiáo em Cabo Verde, conduzido em colaboração com Pierre-Joseph Laurent (UCL-LLN) e Claudio Furtado (UniCV - Praia). Que eles se sintam aqui agradecidos pelos conselhos preciosos e debates estimulantes dos quais o artigo presente alimentou-se.
}

Debates do NER, Porto Alegre, ano io, N. I6, P. I2I-I37, JUl./DeZ. 2009 


\section{ESCRAVATURA, MIGRAÇÃO E ESPIRITUALIDADE EM CABO-VERDE}

De acordo com a tese oficial portuguesa, quando as ilhas do arquipélago de Cabo Verde foram descobertas pelos navegadores portugueses, em $1460^{2}$, elas se encontravam desabitadas. Para assegurar sua ocupação, administração e exploração econômica, a Coroa portuguesa mandou para lá algumas famílias nobres portuguesas, assim como centenas de escravos africanos provenientes da Guiné. Segundo um historiador do começo do século XX, Ernesto de Vasconcelos, a colonização das ilhas fez-se

por occasião de alguns familiares e creados do Infante D. Fernando, que recebera a doação d'ellas, serem por elle mandados para alli com obrigação de as povoarem, para o que elles levaram alguns casaes do Algarve e do Alentejo, e, como já ao tempo se traficasse na Guiné, juntaram-lhe casaes das tribus balantas, papeis, bijagoz, alguns felupes e jalofos, os quaes foram uns e outros os progenitores dos actuais caboverdeanos" (Vasconcelos 1903, p. 33).

Portanto, o seu povoamento organizou-se na maior hibridez, da qual a língua crioula é uma das heranças.

Alem disso, surgiu nestas ilhas uma estação de natureza geopolítica; sendo estrategicamente situadas numa trajetória retilínea entre África e as Américas, se tornaram um lugar de escala inevitável do abastecimento e do negócio dos escravos antes de enviá-los para os seus destinos finais. Era a oportunidade para adquirir os "panos" famosos usados como unidade monetária, mas também para ladinizar ${ }^{3}$ os escravos e, assim, aumentar o seu valor. Nestas condiçốes, as ilhas não tardaram em sobrepovoar-se: colonos, comerciantes, padres e escravos chegaram em massa à Cidade Velha. Em

\footnotetext{
${ }^{2}$ Notemos as contradições da documentação em torno do problema da descoberta dessas ilhas. Quanto aos descobridores, a divergência das opinióes gira em torno de Vicente Dias, Luís de Cadamosto, Diogo Gomes e António de Noli, e, no que diz respeito às datas, apontam-se ora 1445 ora 1456 , ou, ainda, 1460.

${ }^{3}$ Ladinizar os escravos consistia em batizá-los e ensinar os rudimentos de português para aumentar o seu valor no comércio.
}

Debates do NER, Porto Alegre, Ano io, N. I6, P. I2I-I37, JUl./Dez. 2009 
conseqüência, extraíram-se de maneira abusiva recursos naturais (algodão, cana-de-açúcar, fruteiras) ; as águas subterrâneas secaram, a pesca foi praticada em excesso, os prados foram invadidos por uma criação intensiva de gados e cabras. Em dois séculos, essa "economia de predação" se encarregou de explorar até a exaustão essas terras pobres e áridas.

Quando paralelamente novos acordos foram assinados com a Holanda - cujas tecnologias modernas de navegação não requeriam mais a escala em Cabo Verde - o lugar caiu em desuso. Cidade Velha se transformou numa ilha de fantasmas. Quando ela paulatinamente foi repovoada, passou por uma sucessão de secas e escassês, como se fosse uma vingança da sua exploração. Entre 1946 e 1948, a crise foi tão forte que mais de 20\% da população morreu de fome (Carreira, 2000, p. 208-209). Essa escassês conduziu a uma emigração massiva na direção de São Tomé e Príncipe, da qual a voz de Cesária Évora conta a saudade terrível ${ }^{4}$.

Porém, foi a penas o começo de uma emigração sem fim que, ainda hoje, leva 800.000 Cabo-verdianos fora da sua terra-mãe; dois terços da população migra todo o ano, principalmente para os Estados Unidos, Portugal, Holanda e Itália. A paisagem é marcada por casas inacabadas, bairros fantasmas, histórias abortadas, sonhos de migrantes, saudades de amantes que nunca mais voltaram.

$\mathrm{Na}$ dispidida m ka crê margura

Nem sodade dum vida sonhod?

$M$ crê ligria dum vida vivido

Embalod n'ondas di destino ${ }^{5}$

Ildo Lobo, Nha Testamento

A emigração é uma fatalidade; a transnacionalização, uma condição.

${ }^{4}$ Quem te mostrou esse caminho longe? Esse caminho Pra São Tomé. Saudade, saudade, saudade dessa minha terra de São Nicolau. Se tu me escreves Vou te escrever. Se tu me esqueces Vou te esquecer. Até o dia Que vais voltar.

${ }^{5} \mathrm{Na}$ hora da despedida, não quero amargura nem saudade de uma vida sonhada, mas quero a alegria de uma vida vivida, embalada nas ondas do destino.

Debates do NER, Porto Alegre, Ano io, N. I6, P. I2I-I37, JUl./DeZ. 2009 
Cada vez mais se aposta nas espiritualidades como elementos de recriação de laços além das fronteiras. É necessário dissimular o deslocamento - familiar, geográfico, racial, identitário - aproximando os espíritos, universalizando os ritos, usando meios de comunicação imateriais, integrando no mesmo cenário lógicas de origem diferente. Em Cabo Verde, esta tendência é ainda mais natural do que a forma do "crer", posto que a vida nas ilhas conquistou-se desde as origens na encruzilhada entre a África, a Europa e as Américas.

A cidade de Mindelo, capital da ilha de São Vicente - que também foi a última a ser povoada - parece ainda mais particularmente esquartejada entre um modo ocidental e africano de pensar. Por um lado, a cidade estabeleceu-se enquanto foco intelectual e intercultural de Cabo Verde ${ }^{6}$, e, por outro lado, permanece intimamente impregnada por uma consciência persecutória. No que concerne a espiritualidade e as concepçôes da cura, São Vicente está a distância igual da África e da Europa.

Neste contexto híbrido, parece interessante analisar o sucesso e a expansão, principalmente pela diáspora caboverdiana, do movimento do racionalismo cristão.

\section{FUNDAÇÃO DO RACIONALISMO CRISTÃO - BRASIL/CABO VERDE}

De acordo com a versão comumente aceita, a doutrina do racionalismo cristão foi fundada em 1910 pelo respeitado Luiz de Mattos. Este português, eque migrou ao Brasil com treze anos de idade, é descrito como próspero e humanista, generoso e comprometido, dedicado à luta epela causa dos escravos no Brasil. Abolicionista fervoroso, tenta dirigi-los aos "Quilombos", estes acampamentos isolados nas montanhas onde eles eram protegidos pelo

\footnotetext{
${ }^{6}$ Notadamente com a criação por Baltazar Lopes da Silva, em 1917, do primeiro liceu, que atrai a elite das diferentes ilhas. Amilcar Cabral, estudará nesse liceu e valorizará seu papel chave na democratização do conhecimento em Cabo Verde. Mindelo, cosmopolita e intercultural, é assim considerada como o foco de emergência do movimento literário "Claridade".
}

Debates do NER, Porto Alegre, ano io, N. I6, P. I2I-I37, JUl./Dez. 2009 
movimento anti-escravagista. Livre pensador, considera-se ateu até o dia em que um ataque cardíaco o faz questionar todas suas crenças. Essa situação enseja o começo de uma intensa meditação sobre a vida além da matéria, que o levará a assistir pela primeira vez a uma sessão espírita. Este dia, o seu destino subitamente mudou. Ao passar pela porta de entrada, uma pessoa o interrompe para lhe transmitir a mensagem seguinte: o Presidente Astral deste centro espiritualista, Pai Antônio Vieira, ordena que o senhor aceite a presidência dos trabalhos deste centro. Sob a pressão desta pessoa e dos seus dois amigos, Luiz de Mattos finalmente aceita assumir este papel.

Porém, ele não adere aos conteúdos místicos da doutrina e empreende um estudo vasto para defender o espiritualismo enquanto ciência real. Esta dissidência o leva definitivamente fora do espiritismo kardecista - que prega o "evangelho novo" de Allan Kardec - para edificar uma filosofia espiritualista feita de princípios exclusivamente racionais e cristãos. Dois anos depois, o Centro inicialmente chamado "Centro Espírita Amor e Caridade" (1910) é transferido ao Rio de Janeiro e transformado em "Centro redentor" do "espiritualismo racional e científico (cristão)" - posteriormente rebatizado "racionalismo cristão".

Esta narrativa fundadora é uma versão estandardizada apresentada no site do movimento (http://www.racionalismo-cristao.org.br), traduzido em seis línguas e de impacto internacional. Porém, é necessário reconhecer que, de uma casa para o outra, a narrativa conhece variaçóes significativas. Em Cabo Verde, tanto em Praia quanto em Mindelo, pude notar a êmfase colocada numa figura não identificada na versão prévia, ou seja, o presidente do centro espiritualista onde o Luiz de Mattos teria entrado pela primeira vez e recebido a ordem de aceitar a presidência do centro. Trata-se de Augusto Messias de Burgos, mais conhecido sob o nome de Maninho de Burgo, um imigrante Cabo-verdiano praticando já o espiritualismo de acordo com as regras que iam formar o chamado "racionalismo cristáo". Ao contrário da versão exposta no site Web da doutrina, os três presidentes de casas racionalistas que entrevistei em Cabo Verde atribuíram a origem da prática racionalista a este Cabo-verdiano, assim como sublinharam sua influência decisiva na formação e no destino de Luiz de Mattos.

Debates do NER, Porto Alegre, ANo io, N. I6, P. I2I-I37, JUl./DeZ. 2009 
Além deste componente cabo-verdiano inicial, é necessário especificar que desde sempre a expansão da doutrina no Brasil permaneceu simbolicamente e politicamente marginal, em comparação a Cabo Verde, onde faz parte integrante da sociedade. Ali, cada um tem, nos seus parentes ou próximos, um ou vários membros do racionalismo cristão, e ninguém ignora os princípios básicos da doutrina. Os centros são imponentes e abundantemente freqüentados. $\mathrm{O}$ arquipélago conta com 33 centros $^{7}, 7$ dos quais se situam em Mindelo (70.000 habitantes). Além disso, João Vasconcelos nota que a expansão da doutrina no exterior deve-se essencialmente ao trabalho de Cabo-verdianos radicados nos Estados Unidos, Senegal, Angola, Portugal, Holanda, Suíça, França, Luxemburgo e Suécia (Vasconcelos 2005, p. 118). Este autor nota especificamente que $90 \%$ das cartas recebidas pela Casa-chefe no Rio provém de Cabo-verdianos disseminados no mundo inteiro. Isto o conduz a afirmar que "fora do Brasil, o racionalismo cristão tornou-se num movimento cabo-verdiano" (Vasconcelos, 2005, p. 8).

Este artigo tentará entender porque a doutrina faz particularmente eco aos Cabo-verdianos, nativos e migrantes. Propomos a hipótese de que o sucesso da sua consolidação e transnacionalização é o resultado da tensão que sua prática atualiza entre uma aspiração ao racionalismo ocidental e uma ancoragem espiritualista inconfundível.

\section{CIÊNCIA VERSUS RELIGIÃO}

O racionalismo cristão define-se como uma doutrina filosófica de caráter espiritualista. Portanto, qualquer associação a uma religião é claramente rejeitada, o qualificativo "cristâo" sendo assim explicado:

A palavra CRISTÃO, associada a RACIONALISMO, completa o sentido revelador da Doutrina: um código de conduta que reúne princípios espiritualistas e preceitos do cristianismo. Ser racionalista cristão é viver a vida terrena sob normas espiritualistas do mais alto padrão (Prática do Racionalismo Cristäo, p. 29)

733 centros oficiais, ou seja este número não leva em conta as outras casas de ajuntamento não declaradas como tais mas não menos ativas e atuantes.

Debates do NER, Porto Alegre, Ano io, N. I6, P. I2I-I37, JUl./Dez. 2009 
A noção de "cristão" também se refere ao modelo da perfeição moral deixado por Cristo, considerado como uma alma em sua última encarnação, mas também como "o maior filósofo de todos os tempos" (Mateus). Assim, a doutrina se atribui a missão de "restabelecer a Verdade e reimplantar os magnificos ensinamentos de Jesus na Terra" (Prática...p. 37). Não obstante, ao mesmo tempo, ela deixa claro que Jesus não foi filho de Deus; foi um homem como todos os outros, composto de Força e Matéria (espírito e corpo), nascido de uma fecundação humana normal. Ele não veio ao planeta Terra enquanto "ser divino", nem "por obra e graça do Espírito Santo", assim como não existe "Deus" no sentido das religiôes reveladas. Porém, o racionalismo cristão admite a existência de uma Força Superior denominada "Inteligência Universal" ou "Grande Foco", que irradia sobre todo o Universo. O homem seria uma partícula minúscula dessa força, da qual ele herdaria os atributos.

Todo o desafio será, portanto, aperfeiçoar esses atributos, de reencarnação em reencarnação. Em outras palavras, como resume Mateus, um presidente de casa racionalista cristã em Praia : "sendo uma fração do Grande Foco, a pessoa nasce completa e só precisa da evolução".

\section{FINALIDADE: A ELEVAÇÃO DA ALMA}

Aqueles que vêem no princípio básico da espiritualidade o rumo iluminado da ascensão a planos mais elevados sabem que a vida espiritual é eterna, que a evolução se processa em existências sucessivas e que tanto mais será apressado o progresso individual, quanto mais rápido for o desligamento dos atrativos materiais e terrenos. (Prática do Racionalismo Cristão, p. 21)

Conforme a doutrina, encontram-se em evolução na Terra espíritos de várias classes espirituais, distribuídos numa série de trinta e três classes. De acordo com o grau de desenvolvimento de cada um, os espíritos fazem a sua evolução partindo da seguinte ordem de mundos:

mundos materializados - espíritos da $1^{\text {a }}$ à $5^{\text {a }}$ classe

mundos opacos - espíritos da $6^{\mathrm{a}}$ à $11^{\mathrm{a}}$ classe

Debates do NER, Porto Alegre, ANo io, N. I6, P. I2I-I37, JUl./DeZ. 2009 
mundos brancos - $\quad$ espíritos da $12^{\mathrm{a}}$ à $17^{\mathrm{a}}$ classe

mundos diáfanos _ - espíritos da $18^{\mathrm{a}}$ à $25^{\mathrm{a}}$ classe

mundos de luz puríssima - espíritos da $26^{\mathrm{a}}$ à $33^{\mathrm{a}}$ classe

Os três primeiros mundos, ou seja, as 17 primeiras classes, pertencem à atmosfera da Terra. Somos nós, os seres humanos em reincarnação na Terra. Entre 18 e 33, evoluem só espíritos de luz, tal como Che Guevara, Amílcar Cabral (que lutou pela independência de Cabo-Verde) e outras figuras históricas assim definidas pela Casa-chefe. $\mathrm{Na} 33$, o espírito alcançou a elevação máxima e irreversível, de forma que nunca mais baixará na Terra para deixar mensagens por intermediário dos médiuns, como é o caso de Jesus Cristo. O último objetivo do homem na terra será melhorar sua classe espiritual, segundo o conceito da lei das reencarnações; portanto, toda vida nova é considerada como uma "escola" onde o indivíduo experimenta novas facetas da sua alma para purificá-la, a prazo, dos seus erros. A doutrina apresenta o principio desta elevação da alma de acordo com a visão proclamada por Krishna, três mil anos antes de Cristo:

Quando o corpo morre, se o ser foi esclarecido, a alma ascende às regiōes dos entes puros que possuem o conhecimento da vida. Mas se a alma, quando encarnada, se deixou dominar pelas paixóes, pelos desejos imoderados, é então de novo obrigada a voltar à Terra, para recuperar o tempo perdido. (Racionalismo Cristão - Livro Principal, p.13)

\section{O ESPÍRITO OBSESSOR}

A doutrina do Racionalismo Cristão baseia-se antes de tudo na Lei de atração, ou seja, a idéia de que se atrai conforme a vibração do pensamento. Em conseqüência, pensamentos negativos atraem espíritos negativos que perambulam na atmosfera terrena numa camada chamada de "astral inferior". Ao contrário, o "astral superior" define as regiōes do espaço onde habitam e desenvolvem suas atividades os espíritos evoluídos pertencentes aos mundos espirituais da $18^{a}$ à $33^{a}$ classe evolutiva.

Debates do NER, Porto Alegre, Ano io, N. I6, P. I2I-I37, JUl./Dez. 2009 
Os espíritos que permanecem na atmosfera terrena, após a dita "desencarnação" - ou seja, a morte - o fazem por desconhecimento dos seus deveres ou por apego a pessoas, coisas e prazeres materiais ou, ainda, por estarem possuídos por maus sentimentos e outros estados de perturbação. Seus corpos fluídicos estão de tal maneira materializados que não conseguem se libertar dos laços que os prendem ao ambiente terreno.

Nessas condições não tardam a dar início à sua ação propriamente obsessiva sobre os encarnados, atingindo principalmente aqueles que habitualmente alimentam pensamentos e sentimentos negativos e não possuem esclarecimento sobre a vida fora da matéria. Esses espíritos atuam de modo mais freqüente através da mediunidade intuitiva, comum a todos os seres humanos.

A obsessão pode trazer doenças, levar à loucura ou mesmo até a morte. Curar os obsessores pelas sessões de "limpeza psíquica" é precisamente um dos objetivos maiores do racionalismo cristão. Primeiro, trata-se da identificação dos casos mais urgentes, porque só tem lugar para dois obsessores na mesa. Segundo, organiza-se um corrente de "irradiação" durante o qual os espíritos obsessores falam através dos médiuns e acabam, por ordem do presidente, a ser encaminhados ao seu mundo.

\section{SESSÃO DE LIMPEZA PSÍQUICA NO CENTRO REDENTOR}

"A limpeza psíquica" é considerada como uma prática de higiene mental altamente recomendada pela doutrina para obter equilíbrio interior e tranqüilidade espiritual. Uma sessão demora uma hora e consiste principalmente nas irradiações, que são vibrações espirituais, pelas quais ocorre o arrebatamento de espíritos inferiores para fora da atmosfera terrena. Há três sessóes públicas por semana - segunda, quarta e sexta - que reúnem uma média de 200 pessoas no Centro Redentor. Cada sessão é perfeitamente cronometrada.

As portas abrem às 7 da noite; o público entra aos poucos e vai sentar-

Debates do NER, Porto Alegre, Ano io, N. I6, P. I2I-I37, JUl./DeZ. 2009 
se e esperar silenciosamente até que se enche a mesa retangular de madeira, onde se instalam os médiuns e os membros mais ativos do centro. Eles vão formar, pela força dos seus pensamentos, a "corrente" principal da qual subirá a irradiação coletiva. A atmosfera é meia obscura, a atitude séria e concentrada. Quando chega pontualmente as 20 horas, uma mulher e um homem são puxados pelo braço e colocados na extremidade da mesa. Estes primeiros beneficentes da irradiação esperam assim despedir o espírito inferior que é a causa dos seus sofrimentos. A luz diminui de intensidade. $\mathrm{O}$ presidente bate três vezes com o malho e declara a sessão "aberta". Ele toma uma voz grave e solene, ampliada pelo microfone, e começa a irradiação:

Ao Astral Superior. Grande Foco! Força Criadora! Nós sabemos que as leis que regem o Universo são naturais e imutáveis, e a elas tudo está sujeito. Sabemos também que é pelo estudo, raciocínio e crescimento, derivado da luta contra os maus hábitos e as imperfeiçóes, que o espírito se esclarece e alcança maior evolução. Certos do que nos cabe fazer, e pondo em ação o nosso livre-arbítrio para o bem, irradiamos pensamentos aos Espíritos Superiores para que eles nos envolvam na sua luz e fluidos, fortificando-nos para o cumprimento dos nossos deveres.

Grande Foco! Vida do Universo! Aqui estamos a irradiar pensamentos às Forças Superiores para que a luz se faça em nosso espírito, e tenhamos consciência de nossos erros, a fim de evitá-los e nos fortalecer para praticar o bem.

Depois, um homem chamado "a fechadura" retoma a irradiação e a vai repetindo uma centena de vezes sem parar. Às 8:10, duas marteladas de malho, seguidas pelo som de uma campanha; é a chamada aos espíritos. A mulher situada à direita do presidente começa a falar; ela tem o rosto contorcido, o corpo agitado de espasmos e murmura (cito uma das gravações feitas): "eu errei muito. Eu não queria ir embora. Mas quando eu cheguei aqui, entendi que meu lugar não era mais na terra. Eu quero partir agora, mas não sei como. Me ajuda por favor". O presidente, num tom seguro e paternal, começa a fazer comentários sobre a mensagem deixada: "Com certeza, aqui mesmo está o objetivo do racionalismo cristão. Nós vamos irradiar para chamar o Astral Superior e, junto com sua energia, despedir os espiritos desincorporados

Debates do NER, Porto Alegre, ANo io, N. I6, P. I2I-I37, JUl./Dez. 2009 
até o mundo deles". Um por um, cada médium deixa uma mensagem, sistematicamente comentada através das ditas "doutrinaçōes" improvisadas pelo presidente, pelas quais estão expostos os princípios básicos da doutrina.

Após isso, a "fechadura" retoma em torno de cinquenta irradiações, até chegar às 21 horas. Durante a sessão, ambos os pacientes, pela sua posição estratégica, são os primeiros beneficentes da irradiação coletiva da Mesa. Além disso, eles recebem a cada minuto uma "sacudida" feita pelos "fiscais" que os cercam, a fim de fazer sair o espírito que os atormenta.

\section{HERANÇA OCIDENTAL: CULPABILIDADE E RESPONSABILIDADE}

O Racionalismo Cristão vem afirmando, com apoio nas liçôes do Astral Superior, a verdade sobre a lei das reencarnaçóes e o nulo efeito dos perdóes. É pena que para essa verdade tantos se obstinem em fechar os olhos. Uma vez chegados à convicção, pela iluminação espiritual, de que os erros têm de ser resgatados por quem os pratica, custe o que custar, leve o resgate o tempo que levar, sem nenhuma possibilidade de serem perdoados ou anulados, então um novo critério passará a ser adotado. (Prática do Racionalismo Cristão, p. 21)

O primeiro rasto de uma herança ocidental se encontra no surgimento da responsabilidade individual, característica de um princípio tipicamente monista. Mais precisamente, ela está incorporada numa lei de reencarnaçóes, freqüentemente chamada "Lei de retorno", de acordo com a qual "você colhe o que você planta; semeou espinhos, colhe espinhos". Este provérbio, repetido pelos presidentes de sessão, tem a sua origem numa concepção que recusa literalmente o perdão:

A absolvição dos pecados satisfaz ao rebanho, produzindo grande alívio na consciência deste. A alma fica supostamente livre da culpa. Com essa impunidade que a absolvição lhe assegura, não hesita em cometer novas faltas, novos erros, novos crimes, dos quais sabe que receberá a absolvição quando lhe for dada a extrema-unção, no momento final.

Debates do NER, Porto Alegre, Ano io, N. I6, P. I2I-I37, JUl./DeZ. 2009 
Assim, a doutrina não hesita qualificar o perdão dos pecados de "erro mais grave das religiōes", na medida em que ela permite ao homem descarregar-se das suas faltas numa entidade terceira - ou seja Deus.

É comum atribuir-se a Deus, cujos desígnios afirmam ser impenetráveis, a responsabilidade de grande parte das coisas que acontecem na Terra. Dessa maneira, se uma pessoa da família desencarna, foi Deus quem a levou. Se acontece um desastre, Deus assim o quis. Se alguém escapa de ficar sob as rodas de um automóvel, a Deus passa a ser creditado o salvamento da quase vítima.

A individualidade fica sempre subordinada à ação de uma terceira entidade, e essa subordinação exerce esmagadora influência negativa sobre o espírito. (Racionalismo Cristáo - Livro Principal, pp.29-30).

Cada um aprenderá com os seus erros, sendo confrontado com as suas conseqüências numa incorporação futura. Por isso, encontra-se exatamente na irradiação: "Certos do que nos cabe fazer (...) e pondo em ação o nosso livre-arbitrio para o bem", o senso de responsabilidade no que concerne o cumprimento dos deveres cotidianos.

Para assumir suas responsabilidades, é preciso também assegurar-se na vida cotidiana uma boa "companhia astral", porque pela Lei de atração, atrai-se conforme a vibração do pensamento. Cabe então a cada um irradiar a "frequiência" do bem para atrair espíritos do Astral Superior. Nessa perspectiva, o "Espirito Santo" da religião cristã nada mais é do que um espírito de luz posto em movimento pela irradiação colectiva:

"Quando trabalhamos no racionalismo cristão - o que as religiōes não sabem fazer - nós entramos na frequiência superior do Bem infinito; e uma série de criaturas que emitem ondas numa velocidade superior à da luz, cria um campo magnético; e então os espíritos de luz que Igrejas chamam injustamente "Espírito santo", baixam na planeta Terra em fraçóes de segundos". (Mateus)

Esse pensamento significa que o homem escolhe e controla sua "com-

Debates do NER, Porto Alegre, ANo io, N. I6, P. I2I-I37, JUl./Dez. 2009 
panhia astral", ou seja, as energias que vão atuar na sua vida. No cotidiano, trata-se de adotar uma disciplina que seja suficiente para afastar o astral inferior. Isto significa, notadamente, irradiar de manhã à anoite, assim como antes de cada refeição, e assegurar-se uma freqüentação regular das sessóes de limpeza psíquica. Também é preciso adotar uma série de regras normativas de conduta, cujas condições estão bem estabelecidas através de centena de escritos doutrinários - todos acessíveis no site - mas também nos artigos do jornal "A razão", durante o seu programa de rádio - Razão para viver, assim como no conteúdo das comunicaçôes doutrinárias transmitidas em sessão pelos médiuns.

Esta visão do "livre-arbítrio" vale durante mas tambeém depois da incorporação na terra. $\mathrm{O}$ indivíduo não só escolhe a sua companhia, mas sobretudo determina pessoalmente, na hora imminente da nova encarnação, que tipo de vida vai impor-se de acordo com os erros cometidas no passado:

Não é um tribunal astral, como se poderá supor, que vai impor ao delinqüente a justiça espiritual. É o próprio espírito que a ela voluntariamente se submete, no momento em que - livre de todas as influências deste mundo - procede a detido exame de seus atos, quando nem um só escapa à sua apreciaçáo e ao seu julgamento.

O remorso, nessa ocasião, lhe queima a consciência, como se sobre ela tivesse sido posto um ferro em brasa. Dominado pelo arrependimento, anseia por nova encarnação, disposto a dar o máximo de si para recuperar, o mais rápido possível, o tempo que perdeu na Terra.

Esta ênfase colocada no livre-árbitro encarna uma visão profundamente ocidental do peso da responsabilidade individual. Sabendo o perfil dos presidentes de sessão - geralmente de formação superior, leitores fervorosos dos filósofos das Luzes e geralmente bastante prósperos financeiramente ${ }^{8}$ -

${ }^{8}$ Não há nenhuma contribuição dos fiéis; são os presidentes qui financiam inteiramente o aluguel da sala, suas viagens para a Casa-Chefe no Brasil, etc.

Debates do NER, Porto Alegre, Ano io, N. I6, P. I2I-I37, JUl./DeZ. 2009 
podemos entender como tal modo de pensar pode fazer eco neles. Porém, não podemos esquecer que grande parte dos membros é constituída por pessoas modestas que vêm procurar a cura e a resolução de conflitos, até mesmo de dramas quotidianos. Além disso, os médiuns, que estão no coração do processo de "limpeza psíquica", são principalmente donos de casas marginalizadas, às vezes analfabetos, que interpretam a sua vida de acordo com um imaginário de perseguição.

Nessa altura, surge a dimensão mais popular da doutrina, que limita a responsabilidade do homem em seu destino. O "inimigo" está sempre alerta e aproveita da menor fraqueza para intrometer-se. Se o homem pode proteger-se disto pela escolha deliberada da sua "companhia astral", sempre há um momento de desatenção durante o qual o espírito inferior pode interferir. Isto acontece especialmente quando uma legião de espíritos inferiores for enviada por um terço ciumento, na consulta mágica de um curandeiro, ou "mestre".

\section{HERANÇA ESPIRITUALISTA: DUALISMO CORPO-MATÉRIA}

Dona Guida, médium durante 40 anos no Centro o Redentor, me explica, por exemplo, que sempre sentiu-se diferente dos outros porque desde pequena ouve vozes, tem visóes premunitórias e sente formas pretas que correm atrás dela. A história sintomática de sua vida é a do ódio que o leva seus sogros, que sempre a trataram de "bicha" e teriam tentado afetá-la por uma feitiçaria comandada na Guiné. Mas, como está acompanhada do astral superior, esse trabalho nunca deu resultados.

E esta consciência persecutória também é reconhecida pelo contingente mais intelectual da doutrina porque o presidente interpreta nestes termos o fracasso da nossa psiquiatria:

Os psiquiatras vão buscar as causas da loucura nos traumas, na história pessoal, familial (...). E assim fica fraca porque só usa compromissos que agem no sistema nervoso da pessoa mas nada que aja no afastamento do espírito obsessor que, porem, é a única causa real do mal. (Mateus)

Debates do NER, Porto Alegre, Ano io, N. I6, P. I2I-I37, JUl./DeZ. 2009 
Mais precisamente, o pior espírito obsessor seria aquele animado de uma missão, ou seja, comandado por um mestre ou curandeiro. Sobretudo as pessoas que praticam a magia negra seriam mais freqüentemente imigrantes da Guiné ou então Cabo-verdianos formados por chefes guineenses. O esquema persecutório é assim abundantemente mobilizado, ao mesmo tempo em que a origem dele é transferida fora de Cabo Verde, ou seja, à imigração dos africanos do continente nas ilhas. E esta concepção é acompanhada de um julgamento moral negativo atribuído mais geralmente ao modo de vida das sociedades africanas.

$\mathrm{Na}$ África, eles vão pensar: "tal espírito levou meu filho, isso é a culpa de Deus ou de tal espírito? Eles acabam por aceitar isso e avançar assim. Portanto, os africanos precisam conhecer o racionalismo cristão porque vão conhecer-se melhor e valorizar o conhecimento, a luta para a resolução dos problemas da vida. Porque a filosofia tem que ser útil não somente ao mundo inteiro mas especialmente aos povos mais atrasados na sua evolução, no seu progresso material; porque realmente muda a mentalidade (Mateus).

A desresponsabilização por um terço ("isso è a culpa de Deus ou de tal espirito") é considerada um obstáculo para o progresso espiritual e material, mas, ao mesmo tempo, nenhum racionalista cristão nega o perigo, assim como a eficiência, dos curandeiros, mestres, macumbeiros e outros instrumentos ditos do "astral inferior". Pelo contrário, Mateus insiste no fato de que eles são "a pior maldição da humanidade", portanto os primeiros apontados nas sessôes de limpeza psíquica. De fato, vemos que o objetivo de responsabilidade na elevação da alma não evacua em nada o esquema da perseguição.

\section{CONCLUSÃO: ESTACAS SIMBÓLICAS DO RACIONALISMO CRISTÃO}

O Cabo-verdiano parece profundamente esquartejado entre uma lógica de unificação da pessoa - característica do monismo ocidental - e uma lógica

Debates do NER, Porto Alegre, ANo io, N. I6, P. I2I-I37, JUl./DeZ. 2009 
de distinção espírito/matéria - característica do dualismo africano. A aspiração à elevação da sua alma requer a primeira lógica, quando a ancoragem tradicional numa narrativa persecutória requer o segundo. A habilidade do racionalismo cristão é cuidar disto para que estas duas lógicas convirjam num propósito comum, universal, e, transcendendo as fronteiras, irradiar o Bem Infinito para purificar toda a atmosfera da Terra dos espíritos inferiores.

É como se a universalidade do objetivo, a urgência e a amplitude da tarefa, criasse a justificação do uso de um arsenal mais híbrido, para não dizer contraditório. Neste articulação produtiva, a luta é conduzida tanto por uma irradiação como por uma dessobsessão teatral, ao passo que as categorias do pensamento alternam um senso racional da responsabilidade com uma perseguição incontrolável pela bruxaria.

Além da articulação dessas lógicas, a doutrina procede à sua organização hierárquica e projeção num mundo transnacionalizado. Efetivamente, a racionalidade ocidental, apresentada com uma valência positiva (enquanto aspiração), corresponde também ao fluxo da emigração para o Ocidente. Ao contrário, a perseguiçáo pelo feitiço, apresentada como uma valência negativa (enquanto herança - África - por um determinismo geográfico, histórico e cultural, do qual não se pode escapar), corresponde ao fluxo da imigração nas ilhas da África continental, principalmente da Guiné. Assim, articulando uma emigração idealizada com uma imigração diabolizada, o discurso racionalista cristão oferece, de um certo modo, uma interpretação dos fluxos migratórios, assim como da identidade híbrida do Cabo-verdiano.

Esta estaca transnacional na doutrina é confirmada por uma segunda manifestação, ou seja, a sessão de "desdobramento". Nesta ocasião, o médium deixa o seu próprio corpo para sair irradiando além das fronteiras e, assim, curar males no mundo inteiro. Teoricamente, não há alguma identificação clara das estacas transnacionais tratadas nestas sessóes, porque o espírito supostamente esquece da sua viagem assim que volta a um consciente. Porém, Dona Guida me confidenciou que alguns médiuns muito avançados - aos quais ela se associa - podem lembrar-se de certos lugares visitados. Aprofundando o assunto, ela descreve expedições mentais até a guerra no Iraque: reunióes governamentais importantes, sequesto de jovens e ataques

Debates do NER, Porto Alegre, ano io, N. I6, P. I2I-I37, JUl./DeZ. 2009 
diversos. Ela conta também numerosas viagens para as terras da diáspora cabo-verdiana a fim de ajudar os migrantes em dificuldade.

Por estas missões transnacionais, o racionalismo cristão anuncia-se enquanto espiritualidade deslocalizada, fazendo convergir até um bem comum todos os seres humanos, e, mais especificamente, os nativos e migrantes cabo-verdianos.

Em suma, a doutrina simplesmente apresenta-se como a ligação espiritual entre o Cabo Verde e o mundo inteiro.

\section{REFERÊNCIAS BIBLIOGRÁFICAS}

BASTIDE, Roger. Les religions africaines au Brésil. Paris, PUF, 1960.

CARREIRA, Antonio. Cabo Verde, Formação e extinção de uma sociedade escravocrata (1460 - 1878). Praia, IPC, 2000.

PLAIDEAU, C., LAURENT, P-J, FURTADO, C., "L'Eglise Universelle du Royaume de Dieu du Cap-Vert. Croissance urbaine, pauvreté et mouvement néo-pentecôtiste”. Bulletin de l'APAD, n²9-30, «Entrepreneurs et entreprises en quête de normes", p.19-39.

PLAIDEAU, Charlotte. "O Diabo amarrado" ou la guerre néopentecôtiste contre les démons afro-brésiliens (Bahia-Brésil), Tese(Doutorado) - Universidade Católica de Louvain, Louvain-La-Neuve, 2008.

RATIONALISME CHRÉTIEN - LIVRE PRINCIPAL, Gráfica Portinho Cavalcanti, p.30.

VASCONCELOS, João. Langue des esprits et esprit de São Vincente (îles du Cap-Vert), In: Terrain, n. 41, mars 2005, p.109-124.

VASCONCELOS, João. Learning to be a proper medium: middle class womanhood and spirit mediumship in Cape Verde, Working paper presented at the international symposium LEARNING RELIGION: ANTHROPOLOGICAL APPROACHES, organized by Ramon Sarró and David Berliner at the ICS, University of Lisbon, 8-10 September 2005.

Debates do NER, Porto Alegre, Ano io, N. I6, P. I2I-I37, JUl./DeZ. 2009 
